\title{
Severe acute respiratory syndrome coronavirus 2 and influenza $A$ virus co-infection in a nine-year-old boy from a family cluster - case report
}

\author{
Anna Tomasik ${ }^{1,2}$, Maria Pokorska-Śpiewak ${ }^{1,3}$, Ewa Talarek ${ }^{1,3}$, Magdalena Marczyńska1,3 \\ 'Regional Hospital of Infectious Diseases in Warsaw, Warsaw, Poland \\ ${ }^{2}$ Doctoral School, Medical University of Warsaw, Warsaw, Poland \\ ${ }^{3}$ Department of Children's Infectious Diseases, Medical University of Warsaw, Warsaw, Poland
}

\section{ABSTRACT}

In this case report we present a nine-year-old boy from a family cluster with SARS-CoV-2 and influenza virus co-infection. He presented with the most common manifestations of COVID-19 reported in paediatric population - fever and cough. Severe acute respiratory syndrome coronavirus 2 infection was diagnosed by RT-PCR assay, and influenza type A by rapid immunochromatic assay testing. The course of disease was mild, despite co-infection with two viruses. In the time of COVID-19 pandemic testing for influenza, respiratory syncytial virus (RSV), and SARS-CoV-2 in suspected cases is essential for establishing a diagnosis, and it has important implications for patient management.

KEY WORDS:

COVID-19, influenza, co-infection, severe acute respiratory syndrome coronavirus 2 , children.

\section{INTRODUCTION}

Severe acute respiratory syndrome coronavirus 2 (SARS-CoV-2) emerged in China in December 2019 and then spread rapidly to other countries. In March 2020, the World Health Organisation declared a pandemic caused by the novel virus [1]. Coronavirus disease 2019 (COVID-19) affects more commonly and more severely adult persons. The clinical course in children seems to be milder than in adults and is suggestive for other infections. In this case report we present a paediatric patient with SARS-CoV-2 and influenza virus co-infection.

\section{CASE REPORT}

On April 2nd 2020 a nine-year-old boy was referred to the Department of Children's Infectious Diseases, Medical
University of Warsaw, Poland on the first day of fever to $40.5^{\circ} \mathrm{C}$. He had no history of cough, rhinitis, shortness of breath, or other complaints. There was no history of known exposure to confirmed SARS-CoV-2 infection or history of travelling abroad. He had stayed at home for the previous two weeks. He had not received a seasonal $(2019 / 2020)$ influenza vaccine. His past medical history was not significant.

On admission, he was in a good general condition, with body temperature of $37.5^{\circ} \mathrm{C}$, with heart rate $106 / \mathrm{min}$, respiratory rate $30 / \mathrm{min}$, and oxygen saturation on room air of $99 \%$. Physical examination showed erythematous throat and tonsils, with no other abnormalities.

Due to the epidemiological situation, a nasopharyngeal swab was collected for SARS-CoV-2 reverse-transcriptase-polymerase-chain-reaction (RT-PCR) assay, and for influenza rapid immunochromatic assay testing.

\section{ADDRESS FOR CORRESPONDENCE:}

Anna Tomasik, Regional Hospital of Infectious Diseases, 37 Wolska St., 01-201 Warsaw, Poland, ORCID: 0000-0003-0288-9790, e-mail: atoma2903@gmail.com 
The result of the second test was positive for influenza A virus. Paracetamol and antiviral therapy with oseltamivir were implemented. He did not require hospitalisation and was sent home for isolation. A positive result of SARSCoV-2 RT-PCR test was received 24 hours later. Then the boy was admitted to the hospital in order to perform further diagnostics and chest imaging. On admission, he reported dry cough. He had no fever and did not report shortness of breath or any pain. Physical examination revealed no abnormalities. Laboratory testing results are presented in Table 1. A chest X-ray was performed and showed no abnormalities.

According to the Health Care Standard for Children with COVID-19 in Poland at that time, a three-day course of azithromycin (10 mg/kg once daily) was implemented. Oseltamivir was continued. Due to a good general condition, the boy was discharged home to continue treatment. His parents were informed about the principles of monitoring boy's condition at home. They were asked to note his symptoms, fluid intake, and body temperature and report observations by phone to the ward doctor twice a day.

On the day the boy was diagnosed for COVID-19, the patient's family members were tested for SARS-CoV-2 infection, and it was confirmed in the father, who reported two-day history of fever, cough, and shortness of breath. In the mother (complaining of rhinitis) and 20-year old brother (reporting an episode of low fever) results of SARS-CoV-2 RT-PCR testing were negative.

During a two-week home isolation the boy was afebrile, without any other symptoms. He reported an episode of abdominal pain after the last dose of azithromycin, but it resolved spontaneously. He did not report any other complains. A nasopharyngeal swab for SARSCoV-2 RT-PCR testing obtained 14 days after the first

TABLE 1. Laboratory testing results

\begin{tabular}{|l|c|}
\hline Test (reference range) & Result \\
\hline White blood cells $\left(4-10,000 \times 10^{9} / \mathrm{l}\right)$ & 4,600 \\
\hline Platelet count $\left(150-350 \times 10^{3} / \mu \mathrm{l}\right)$ & 251 \\
\hline Haemoglobin $(11.5-15.5 \mathrm{~g} / \mathrm{dl})$ & 12.2 \\
\hline Neutrophil count $(2-45 \mathrm{cell} / \mathrm{s} / \mathrm{l})$ & 1.59 \\
\hline Lymphocyte count $(1.80-3.70$ cells/ $\mu \mathrm{l})$ & 1.86 \\
\hline C-reactive protein $(<10 \mathrm{mg} / \mathrm{l})$ & 15 \\
\hline Glucose $(3.60-5.50 \mathrm{mmol} / \mathrm{l})$ & 5.31 \\
\hline Urea $(2.50-7.10 \mathrm{mmol} / \mathrm{l})$ & 4.78 \\
\hline Creatinine $(58-110 \mathrm{mmol} / \mathrm{l})$ & 41 \\
\hline Lactate dehydrogenase $(120-246 \mathrm{U} / \mathrm{l})$ & 212 \\
\hline D-dimer $(<500 \mathrm{ng} / \mathrm{ml})$ & 508.55 \\
\hline Aspartate aminotransferase $(10-59 \mathrm{U} / \mathrm{l})$ & 29 \\
\hline Alanine aminotransferase $(4-50 \mathrm{U} / \mathrm{l})$ & 16 \\
\hline
\end{tabular}

one showed a negative result. The control swabs were also negative in both parents. However, the 20-year-old brother had a positive test result for SARS-CoV-2 14 days after the initial testing.

\section{DISCUSSION}

On April 2 $2^{\text {nd }}$, when our patient was admitted, there were almost 3000 cases of confirmed SARS-CoV-2 infection in Poland [2].

In the presented case the initial suspicion of SARSCoV-2 infection was based on the current epidemiological situation in Poland. Despite the fact that the boy was coinfected with two viruses, the novel coronavirus and the influenza A virus, the course of disease was mild. This aligns with the early data reporting less severe effect of novel coronavirus in children than in adults $[3,4]$. The patient presented with the most common manifestations of COVID-19 reported in paediatric population - fever and cough [5]. There are no laboratory findings characteristic enough to differentiate SARS-CoV-2 infection from other viral infections. Children with more pronounced symptoms might be suspected of coinfection with another pathogen. In the systemic review of COVID-19 in 1183 paediatric patients the coinfection with another pathogen was observed in 5.6\% (72/1183) of children. Mycoplasma and influenza were the most common coinfections [6].

Oseltamivir was implemented at the first day of infection symptoms, as a treatment for influenza. Coronaviruses do not utilise neuramidase, and there are no data suggesting in vitro activity of oseltamivir against SARS-CoV-2 [7, 8]. After the positive result for SARSCoV-2 was obtained, azithromycin was used empirically due to its suspected effective role in prevention of severe lower respiratory tract illness $[9,10]$. Neither World Health Organisation nor US Centre for Disease Control and Prevention recommend any specific treatment for SARS-CoV-2 infection in children [5]. Protocols of management for children with COVID-19 are formed locally and based on very limited data, and thus vary between countries and clinics.

The infection with SARS-CoV-2 in children is suspected to originate mainly from infected family members. In this case both parents were attending work at the time of pandemic and were potentially exposed to the SARSCoV-2 infection. Implementation of mitigation interventions in Poland such as school closures, cancellation of mass gatherings, and closure of public places was initiated on March $13^{\text {th }} 2020$. The patient reported to the ward on April $3^{\text {rd }}$; therefore, he was not exposed to peers for around 20 days. In this particular family cluster SARSCoV-2 infection was initially confirmed in the patient and his father. The older brother had the infection confirmed in control swab after 14 days. Interestingly, the mother had two negative test results for SARS-CoV-2, regardless 
of affected household contacts. More and more evidence points to the origin of infection in children from family cluster outbreaks. The role of children in transmission of the virus and the period of communicability requires further investigation.

There are very few published studies involving COVID-19 in the paediatric population. Most of them had a short observation period. The largest sample sizes were obtained in China, so population differences have to be considered, and results cannot be generalised. To date, there is only one case report on SARS-CoV-2 and influenza virus coinfection in a four-month-old infant with a mild disease course [11] and one report on adult coinfection leading to intubation due to a significant delay in COVID-19 detection [12]. The issue was brought up by Wu et al., who underlined that in a case of positive test for influenza, the SARS-CoV-2 infection should not be automatically excluded [13]. Screening of people with fever, cough, or sore throat for both viruses with oral and nasopharyngeal swabs is necessary in the current epidemiological situation.

SARS-CoV-2 virus emerged at the peak of the influenza and Respiratory Syncytial Virus (RSV) infections season in the northern hemisphere, all of which manifest with very similar symptoms. In conclusion in the time of the SARS-CoV-2 pandemic, paediatricians should not forget about the differential diagnosis, and implement molecular testing for influenza, RSV, and SARS-CoV-2 in suspected cases, because it is essential for the initiation of proper management and treatment. Children from family clusters should be tested for SARS-CoV-2 regardless of clinical presentation. Early studies suggest that coinfecteion with influenza virus does not lead to more severe clinical course of SARS-CoV-2 infection in children [6]. However, seasonal influenza vaccination in children can protect the paediatric population from coinfection in $\mathrm{fu}$ ture outbreaks of other viral diseases.

\section{DISCLOSURE}

The authors declare no conflict of interest.

\section{REFERENCES}

1. World Health Organization. Coronavirus disease (COVID-19) pandemic. https://www.who.int/emergencies/diseases/novel-coronavirus-2019 (access: 26 May 2020).

2. Center for Systems Science and Engineering (CSSE) at Johns Hopkins University (JHU). Coronavirus COVID-19 global cases by the Center for Systems Science and Engineering (CSSE) at Johns Hopkins University (JHU). Published 2020. https://coronavirus.jhu.edu/ map.html (access: 24 April 2020).

3. Dong Y, Mo X, Hu Y, et al. Epidemiological characteristics of 2143 pediatric patients with 2019 coronavirus disease in China. Pediatrics 2020; 145: e20200702.

4. Rasmussen SA, Thompson LA. Coronavirus Disease 2019 and Children. What Pediatric Health Care Clinicians Need to Know. JAMA Pediatr 2020; 174: 743-744.
5. Zimmermann P, Curtis N. Coronavirus Infection in Children Including COVID-19, an overview of the Epidemiology, Clinical Features, Diagnosis, Treatment and Prevention Options in Children. Pediatr Infect Dis J 2020; 39: 355-368.

6. Hoang A, Chorath K, Moreira A, et al. COVID-19 in 7780 pediatric patients: A systematic review, EClinicalMedicine 2020; 24: 100433.

7. McCreary E, Pogue J. Coronavirus Disease 2019 Treatment: A Review of Early and Emerging Options. Open Forum Infect Dis 2020; 7: ofaa 105

8. Tan EL, Ooi EE, Lin CY, et al. Inhibition of SARS coronavirus infection in vitro with clinically approved antiviral drugs. Emerg Infect Dis 2004; 10: 581-586.

9. Bacharier LB, TW Guilbert TW, Mauger DT, et al. Early administration of azithromycin and prevention of severe lower respiratory tract illnesses in preschool children with a history of such illnesses: A randomized clinical trial. JAMA 2015; 314: 2034-2044.

10. Gautret P, Lagier JC, Parola P, et al. Hydroxychloroquine and azithromycin as a treatment of COVID-19: results of an open-label non-randomized clinical trial. Int J Antimicrob Agents 2020; 56: 105949.

11. Wehl G, Laible M, Rauchenzauner M. Co-infection of SARS CoV2 and influenza $A$ in a Pediatric Patient in Germany. Klin Padiatr 2020; 232: 217-218.

12. Wu X, Cai Y, Huang X, et al. Co-infection with SARS-CoV-2 and influenza A virus in patient with pneumonia, China. Emerg Infect Dis 2020; 26: 1324-1326.

13. Wu D, Lu J, Ma X, et al. Coinfection of Influenza Virus and Severe Acute Respiratory Syndrome Coronavirus 2 (SARS-COV-2). Pediatr Infect Dis J 2020; 39: e79. 